Pacific Journal of Mathematics

MULTIPLICATION FORMULAE FOR THE $E$-FUNCTIONS
REGARDED AS FUNCTIONS OF THEIR PARAMETERS 


\section{MULTIPLICATION FORMULAE FOR THE $E$-FUNCTIONS REGARDED AS FUNCTIONS OF THEIR PARAMETERS}

\section{T. M. MACRoBert}

1. Introduction. The formulae to be proved are

$$
\begin{aligned}
& \sum_{i,-i} \frac{1}{i} E\left(p ; m \alpha_{r}: q ; m \rho_{s}: z e^{i \pi}\right) \\
& \quad=(2 \pi)^{-\frac{1}{2}(m-1)(p-q-1)} m^{m\left(\Sigma \alpha_{r}-\Sigma_{\rho_{s}}\right)-\frac{1}{2}(p-q-1)}
\end{aligned}
$$

$$
\times \sum_{i,-i} \frac{1}{i} E\left\{\begin{array}{l}
\alpha_{1}, \alpha_{1}+\frac{1}{m}, \cdots, \alpha_{1}+\frac{m-1}{m}, \cdots, \alpha_{p}+\frac{m-1}{m}: \\
\frac{1}{m}, \frac{2}{m}, \cdots, \frac{m-1}{m}, \rho_{1}, \cdots, \rho_{q}+\frac{m-1}{m}: \\
\left.\left(\frac{z}{m^{p-q-1}}\right)^{m} e^{i \pi}\right\},
\end{array}\right.
$$

where $n$ is a positive integer, $p>q+1$, and $|\operatorname{amp} z|<1 / 2(p-q-1) \pi$. If $p \leq q+1$, both sides vanish identically.

For all values of $p$ and $q$

$$
\begin{aligned}
& E\left(p ; m \alpha_{r}: q ; m \rho_{s}: z e^{ \pm i \pi}\right) \\
& \quad=(2 \pi)^{-\frac{1}{2}(m-1)(p-q-1)} m^{m\left(\Sigma \alpha_{r}-\Sigma \rho_{s}\right)-\frac{1}{2}(p-q+1)}
\end{aligned}
$$

( 2 )

$$
\times \sum_{n=0}^{m-1}\left(\frac{m^{n-q-1}}{z}\right)^{n} E\left\{\begin{array}{l}
\alpha_{1}+\frac{n}{m}, \cdots, \alpha_{1}+\frac{n+m-1}{m}, \cdots, \alpha_{p}+\frac{n+m-1}{m} \\
\frac{n+1}{m}, \frac{n+2}{m}, \cdots * \cdots, \frac{n+m}{m}, \rho_{1}+\frac{n}{m}, \cdots,
\end{array}\right.
$$

$$
\left.\rho_{q}+\frac{n+m-1}{m}:\left(\frac{z}{m^{p-q-1}}\right)^{m} e^{ \pm i \pi}\right\}
$$

the asterisk indicating that the parameter $\mathrm{m} / \mathrm{m}$ is omitted.

The proof of (1) is based on the formula ([1], p. 374)

$$
E\left(p ; \alpha_{r}: q ; \rho_{s}: z\right)=\frac{1}{2 \pi i} \int \frac{\Gamma(\zeta) \Pi \Gamma\left(\alpha_{r}-\zeta\right)}{I I \Gamma\left(\rho_{s}-\zeta\right)} z^{\zeta} d \zeta,
$$

where the integral is taken up the $\eta$-axis, with loops, if necessary, to ensure that the pole at the origin lies to the left and the poles at 
$\alpha_{1}, \alpha_{2}, \cdots, \alpha_{p}$ to the right of the contour. Zero and negative integral values of the $\alpha^{\prime}$ s and $\rho^{\prime}$ s are excluded, and the $\alpha^{\prime}$ s must not differ by integral values. The contour must be modified if $p<q+1$; and if $p=q+1,|z|<1$; but we are here concerned only with the case $p>q+1$. Then $z$ must satisfy the condition $|\operatorname{amp} z|<1 / 2(p-q+1) \pi$.

From (3) it follows that, if $p>q+1$, |amp $z \mid<1 / 2(p-q-1) \pi$,

$$
\sum_{i,-1} \frac{1}{i} E\left(p ; \alpha_{r}: q ; \rho_{s}: z e^{i \pi}\right)=\frac{1}{i} \int \frac{I I I^{\prime}\left(\alpha_{r}-\zeta\right)}{I^{\prime}(1-\zeta) I I \Gamma^{\prime}\left(\rho_{s}-\zeta\right)} z^{\zeta} d \zeta .
$$

For, on substituting on the left from (3), a factor $\left(e^{i \pi \zeta}-e^{-i \pi \zeta}\right)$ appears in the integral, and

$$
I^{\prime}(\zeta) \sin \pi \zeta=\pi / I^{\top}(1-\zeta) .
$$

The three following formulac ([1], pp. 154, 406, 407) are also required.

If $m$ is a positive integer,

$$
\begin{aligned}
\Gamma^{\prime}(m z) & =(2 \pi)^{\frac{1}{2}-\frac{1}{2} m} m^{m z-\frac{1}{2}} \Gamma^{\prime}(z) \Gamma\left(z+\frac{1}{m}\right) \cdots \Gamma\left(z+\frac{m-1}{m}\right) ; \\
\int_{0}^{\infty} e^{-\lambda} \lambda^{k-1} E\left(p ; \alpha_{r}: q ; \rho_{s}: z / \lambda^{m}\right) d \lambda & \\
& =(2 \pi)^{\frac{1}{2}-\frac{1}{2} m} m^{k-\frac{1}{2}} E\left(p+m ; \alpha_{r}: q ; \rho_{s}: z / m^{m}\right),
\end{aligned}
$$

where $R(k)>0, \alpha_{n+1+\nu}=(k+\nu) / m, \nu=0,1,2, \cdots, m-1$;

$$
\begin{aligned}
& \frac{1}{2 \pi i} \int e^{\zeta \zeta^{-\rho}} E\left(p ; \alpha_{r}: q ; \rho_{s}: \zeta^{m} z\right) d \zeta \\
& \quad=(2 \pi)^{\frac{1}{2} m-\frac{1}{2}} m^{\frac{1}{2}-\rho} E\left(p ; \alpha_{r}: q+m ; \rho_{s}: z m^{m}\right),
\end{aligned}
$$

where the contour of integration starts from $-\infty$ on the $\xi$-axis, passes round the origin in the positive direction, and ends at $-\infty$ on the $\xi$-axis, amp $\xi$ being $-\pi$ initially, and $\rho_{q+1+\nu}=(o+\nu) / m, \nu=$ $0,1,2, \cdots, m-1$.

2. Proofs of the formulae. On applying (4) on the left of (1) and replacing $\zeta$ by $m \zeta$ the left hand side becomes

$$
\frac{m}{i} \int \frac{\pi \Gamma\left(m \alpha_{r}-m \zeta\right)}{\Gamma(1-m \zeta) \pi \Gamma\left(m \rho_{s}-m \zeta\right)} z^{m \zeta} d \zeta .
$$

Here apply (5) and get 


$$
\begin{array}{r}
(2 \pi)^{-\frac{1}{2}(m-1)(p-q-1)} m^{m\left(\Sigma \alpha_{r}-\Sigma_{\rho_{s}}\right)-\frac{1}{2}(p-q-1)} \\
\times \frac{1}{i} \int \frac{I I\left\{\Gamma\left(\alpha_{r}-\zeta\right) \Gamma\left(\alpha_{r}+\frac{1}{m}-\zeta\right) \cdots \Gamma\left(\alpha_{r}+\frac{m-1}{m}-\zeta\right)\right\}}{\Gamma(1-\zeta) \Gamma\left(\frac{1}{m}-\zeta\right) \cdots \Gamma\left(\frac{m-1}{m}-\zeta\right) \Pi\left\{\Gamma\left(\rho_{s}-\zeta\right) \cdots \Gamma\left(\rho_{s}+\frac{m-1}{m}-\zeta\right)\right.} \\
\times\left(\frac{z}{m^{p-q-1}}\right\}^{m \zeta} d \zeta,
\end{array}
$$

and from (4), this is equal to the right hand side of (1).

Formula (2) can be obtained by showing that

$$
\begin{aligned}
& E\left(:: e^{ \pm i \pi} z\right)=e^{1 / z} \\
& =\sum_{n=0}^{m-1} \frac{(1 / z)^{n}}{n !} F\left\{; \frac{n+1}{m}, \cdots * \cdots, \frac{n+m}{m} ;(m z)^{-m}\right\} \\
& =(2 \pi)^{\frac{1}{2} m-\frac{1}{2}} m^{-\frac{1}{2}} \sum_{n=0}^{m-1}\left(\frac{1}{m z}\right)^{n} E\left\{: \frac{n+1}{m}, \cdots * \cdots, \frac{n+m}{m}: e^{ \pm i \pi}(m z)^{m}\right\},
\end{aligned}
$$

and then generalizing by employing (6) and (7).

Note 1. Ragab's formula [2]

$$
\begin{aligned}
& \sum_{i,-i} \frac{1}{i} \int_{0}^{\infty} e^{-p t} E\left(\alpha, \alpha+\frac{1}{m}, \cdots, \alpha+\frac{m-1}{m}:: e^{i \pi} z m^{-m} / t\right) d t \\
& \quad=(2 \pi)^{\frac{1}{2}+\frac{1}{2} m} m^{-m \alpha-\frac{1}{2}} p^{\alpha-1} z^{\alpha} \exp \left(-p^{1 / m} z^{1 / m}\right),
\end{aligned}
$$

where $m$ is a positive integer greater than $1, p$ is positive, $|\operatorname{amp} z|<$ $1 / 2(m-1) \pi$, can be derived by substituting on the left from (4), changing the order of integration, evaluating the inner integral, applying (5), replacing $\zeta$ by $\alpha-\zeta / m$, and applying (3).

Note 2. It has been pointed out by a referee that there seems to be some connection between the formulae of this paper and certain formulae of Meijer's for the $G$-function which are reproduced on pages 209, 210 of the first volume of Higher Transcendental Functions [McGraw Hill Book Co., 1953].

\section{REFERENCES}

1. T. M. MacRobert, Functions, of a complex variable (4th edition, London, 1954).

2. F. M. Ragab, The inverse Laplace transform of an exponential function, New York University, Institute of Mathematical Sciences, Astia Document No. AD 133670. 



\section{PACIFIC JOURNAL OF MATHEMATICS}

\section{EDITORS}

\section{David Gilbarg}

Stanford University Stanford, California

\section{R. A. Beaumont}

University of Washington

Seattle 5, Washington

\section{A. L. Whiteman}

University of Southern California Los Angeles 7, California

L. J. Paige

University of California

Los Angeles 24, California

\section{ASSOCIATE EDITORS}

E. F. BECKENBACH
C. E. BURGESS
E. HEWITT
A. HORN

A. HORN

\author{
V. GANAPATHY IYER \\ R. D. JAMES \\ M. S. KNEBELMAN \\ L. NACHBIN
}

I. NIVEN

T. G. OSTROM

H. L. ROYDEN

M. M. SCHIFFER
E. G. STRAUS

G. SZEKERES

F. WOLF

K. YOSIDA

\section{SUPPORTING INSTITUTIONS}

\author{
UNIVERSITY OF BRITISH COLUMBIA \\ CALIFORNIA INSTITUTE OF TECHNOLOGY \\ UNIVERSITY OF CALIFORNIA \\ MONTANA STATE UNIVERSITY \\ UNIVERSITY OF NEVADA \\ OREGON STATE COLLEGE \\ UNIVERSITY OF OREGON \\ OSAKA UNIVERSITY \\ UNIVERSITY OF SOUTHERN CALIFORNIA
}

\author{
STANFORD UNIVERSITY \\ UNIVERSITY OF TOKYO \\ UNIVERSITY OF UTAH \\ WASHINGTON STATE COLLEGE \\ UNIVERSITY OF WASHINGTON \\ * * * * \\ AMERICAN MATHEMATICAL SOCIETY \\ CALIFORNIA RESEARCH CORPORATION \\ HUGHES AIRCRAFT COMPANY \\ SPACE TECHNOLOGY LABORATORIES
}

Mathematical papers intended for publication in the Pacific Journal of Mathematics should be typewritten (double spaced), and the author should keep a complete copy. Manuscripts may be sent to any one of the four editors. All other communications to the editors should be addressed to the managing editor, L. J. Paige at the University of California, Los Angeles 24, California.

50 reprints per author of each article are furnished free of charge; additional copies may be obtained at cost in multiples of 50 .

The Pacific Journal of Mathematics is published quarterly, in March, June, September, and December. The price per volume (4 numbers) is $\$ 12.00$; single issues, $\$ 3.50$. Back numbers are available. Special price to individual faculty members of supporting institutions and to individual members of the American Mathematical Society: $\$ 4.00$ per volume; single issues, $\$ 1.25$.

Subscriptions, orders for back numbers, and changes of address should be sent to Pacific Journal of Mathematics, 2120 Oxford Street, Berkeley 4, California.

Printed at Kokusai Bunken Insatsusha (International Academic Printing Co., Ltd.), No. 6, 2-chome, Fujimi-cho, Chiyoda-ku, Tokyo, Japan.

PUBLISHED BY PACIFIC IOURNAL OF MATHEMATICS, A NON-PROFIT CORPORATION

The Supporting Institutions listed above contribute to the cost of publication of this Journal, but they are not owners or publishers and have no responsibility for its content or policies. 


\section{Pacific Journal of Mathematics}

\section{Vol. 9, No. $3 \quad$ July, 1959}

Errett Albert Bishop, A minimal boundary for function algebras . . . . . . . . . . . . 629

John W. Brace, The topology of almost uniform convergence . . . . . . . . . . . . 643

Cecil Edmund Burgess, Chainable continua and indecomposability .......... 653

L. Carlitz, Multiplication formulas for products of Bernoulli and Euler

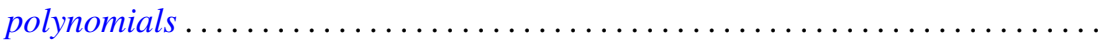

Eckford Cohen, A class of residue systems (mod $r$ ) and related arithmetical

functions. II. Higher dimensional analogues ....................

Shaul Foguel, Boolean algebras of projections of finite multiplicity . . . . . . . . . .

Richard Robinson Goldberg, Averages of Fourier coefficients .................

Seymour Goldberg, Ranges and inverses of perturbed linear operators .

Philip Hartman, On functions representable as a difference of convex functions ....

Milton Vernon Johns, Jr. and Ronald Pyke, On conditional expectation and

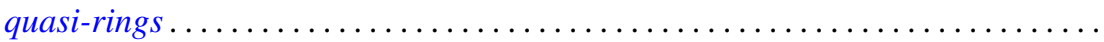

Robert Jacob Koch, Arcs in partially ordered spaces ....................

Gregers Louis Krabbe, A space of multipliers of type $L^{p}(-\infty, \infty) \ldots \ldots \ldots \ldots$

John W. Lamperti and Patrick Colonel Suppes, Chains of infinite order and their

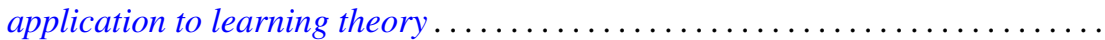

Edith Hirsch Luchins, On radicals and continuity of homomorphisms into Banach

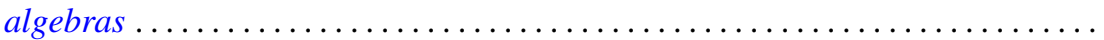

T. M. MacRobert, Multiplication formulae for the E-functions functions of their parameters.

Michael Bahir Maschler, Classes of minimal and representative domains and their kernel functions.

William Schumacher Massey, On the imbeddability of the real projective spaces in Euclidean space.

Thomas Wilson Mullikin, Semi-groups of class $\left(C_{0}\right)$ in $L_{p}$ determined by parabolic differential equations

Steven Orey, Recurrent Markov chains

Ernest Tilden Parker, On quadruply transitive groups ........ . .

Calvin R. Putnam, On Toeplitz matrices, absolute continuity, and unitary

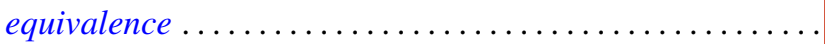

Helmut Heinrich Schaefer, On nonlinear positive operators.

Robert Seall and Marion Wetzel, Some connections between continued fractions and convex sets

Robert Steinberg, Variations on a theme of Chevalley

Olga Taussky and Hans Zassenhaus, On the similarity transformation between a

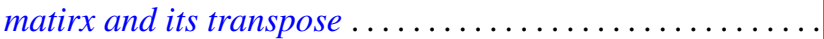

Emery Thomas, The suspension of the generalized Pontrjagin cohomology

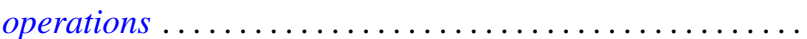

Joseph L. Ullman, On Tchebycheff polynomials ..................... 913

Richard Steven Varga, Orderings of the successive overrelaxation scheme ........ 925

Orlando Eugenio Villamayor, Sr., On weak dimension of algebras . 